\title{
$\infty$ \\ Å BALANSERE PÅ EN KNIVSEGG \\ MOT SOSIALT SAMMENBRUDD BLANT UNGE PALESTINERE I ØST-JERUSALEM
}

\author{
Hvordan forklare den såkalte «knivintifadaen» i Israel og på Vestbredden \\ høsten 2015 og våren 20I6? En analyse av situasjonen for unge \\ i Jerusalem gir svar.
}

JACOB HØIGILT

$\mathrm{H}$

østen og våren 2015-2016 var det en serie

knivangrep mot israelske soldater og sivile.

Angrepene fant sted både innenfor 1948-grensene til Israel og på Vestbredden, inkludert ØstJerusalem. Særlig i begynnelsen kom mange av angriperne fra nettopp denne byen, og de fleste av dem var unge menn i tjueårene. ${ }^{1}$ Derfor er det Øst-Jerusalem jeg skal fokusere på i denne artikkelen. I motsetning til tidligere voldsbølger var det ingenting som tydet på at disse aktivistene var organisert. De var «vanlige folk», handlet alene og ble kalt «ensomme ulver» av israelsk etterretning. ${ }^{2}$ De virket heller ikke spesielt religiøst motivert, selv om flere noterte seg at en gruppe jødiske nasjonalister hadde økt spenningsnivået rundt alAqsa-moskeen og Klagemuren i tiden før angrepene begynte. ${ }^{3}$ Ofte var angriperne tilsynelatende veltilpassede unge som aldri hadde gitt uttrykkk for noen politisk radikalisering. Foreldrene deres var gjerne sjokkert og stilte seg helt uforstående til hva barna deres hadde gjort. ${ }^{4}$

Hvordan kan fenomenet forklares? I det følgende hevder jeg at hovedårsaken hverken er Jerusalems symbolske status eller en militarisering av palestinsk motstand à la Hamas, men snarere en ekstrem marginalisering av unge i ØstJerusalem, sosialt, økonomisk og politisk. Knivangrepene satte søkelys på palestinsk ungdom i Øst-Jerusalem. I akademisk litteratur om konflikten er denne gruppen relativt lite omtalt, men selve marginaliseringen av palestinerne i ØstJerusalem er godt dokumentert gjennom rapporter fra israelske, palestinske og internasjonale organisasjoner. Slike rapporter gir imidlertid ikke forklaringer på politiske handlinger, de gir bare et forklaringsgrunnlag. De sier dessuten lite om den interne palestinske politiske og sosiale dynamikken, som også spiller en viktig rolle.

I denne artikkelen vil jeg beskrive hvordan unge palestinere er marginalisert, hvordan de kjemper mot denne tendensen, og hvordan

'Isawiyya er et distrikt i Øst-Jerusalem der det ofte har vært kraftige sammenstøt. 


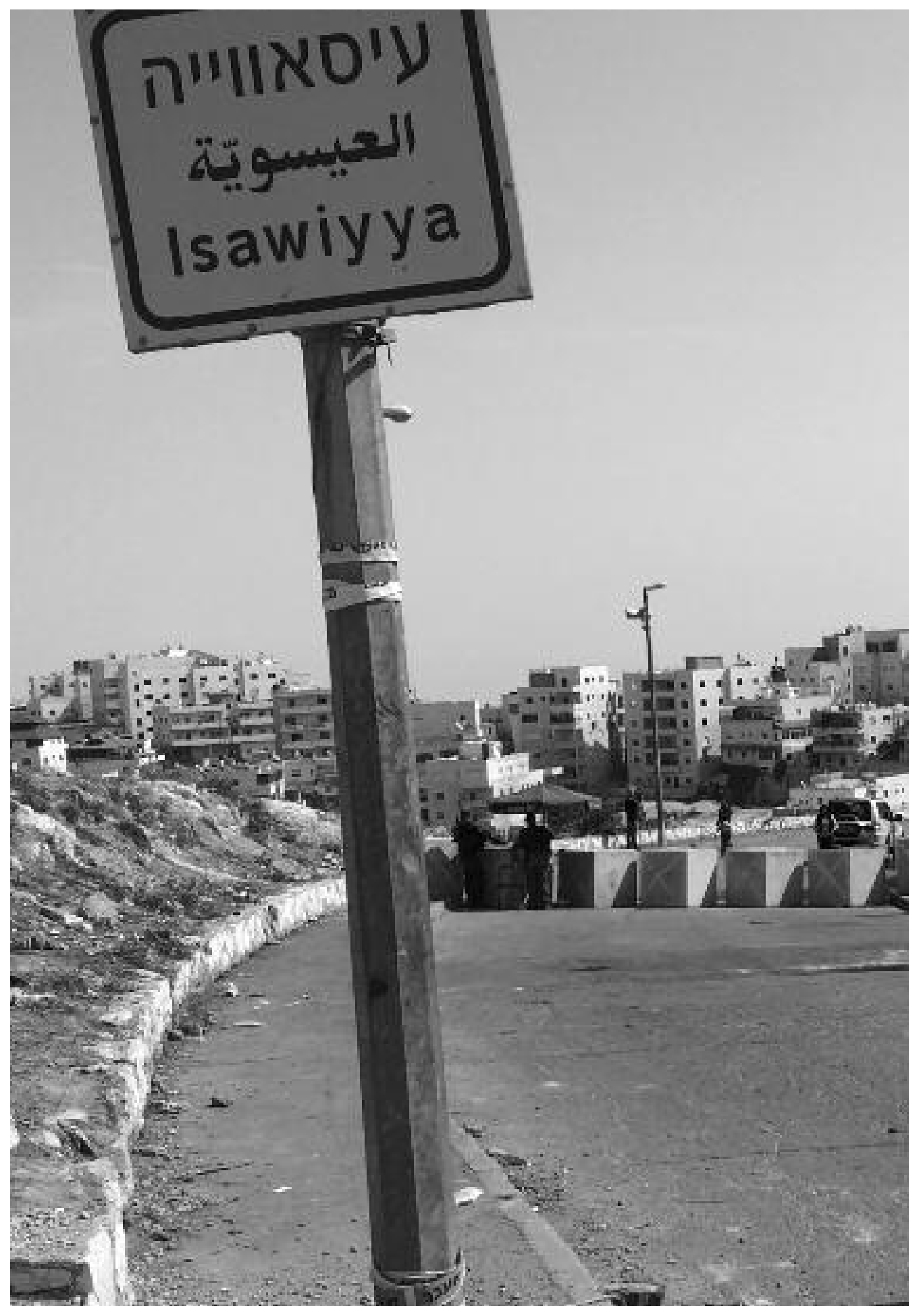


marginaliseringen kan forklare knivangrepene i 2015-2016. Jeg bygger stort sett på intervjuer med grasrotorganisasjoner og feltobservasjoner som jeg samlet inn i løpet av korte feltarbeid våren 20I4 og våren 2015. Det er flere hundre palestinske grasrotorganisasjoner i Øst-Jerusalem. Jeg gjorde et utvalg basert på bakgrunnsinformasjon og tips fra aktivister i De okkuperte palestinske områdene. Under selve feltarbeidene brukte jeg den såkalte snøballmetoden - det vil si at intervjuobjekter foreslo andre organisasjoner de mente ville være interessante for forskningsprosjektet mitt. Samtalene fant sted på arabisk eller engelsk, avhengig av hva respondentene foretrakk. Alle sitater fra begge språk er oversatt av meg. Ingen av organisasjonene jeg beskriver her driver politisk arbeid, og de rapporterte ikke at de ble forfulgt av okkupasjonsmyndighetene, men jeg har valgt å anonymisere informantene.

\section{INGENMANNSLANDET ØST-JERUSALEM}

Unge palestinere i Øst-Jerusalem er dobbelt marginalisert - av Israel og innenfor den palestinske nasjonale bevegelsen. La oss begynne med Israels politikk overfor byen. Israel annekterte Øst-Jerusalem kort etter okkupasjonen i 1967 (ingen andre land har anerkjent anneksjonen, og det internasjonale samfunnet anser byen for å være okkupert). Siden I967 har Israel ført en «judaiserings»-politikk, som i korthet går ut på å få flere jøder og færre palestinere til å bo i ØstJerusalem og endre byens karakter der jødiske bosettere bor slik at den likner mer på det israelske Vest-Jerusalem. Hovedredskapet i denne politikken er bosettinger. De største palestinske bydelene i Øst-Jerusalem er nå omkranset av israelske bosettinger, slik at de er i ferd med å miste den geografiske og sosiale forbindelsen med hverandre. Ifølge den israelske menneskerettighetsorganisasjonen B’Tselem bodde det nærmere 200000 israelske statsborgere i disse bosettingene i 20I2, og tallet øker hvert år. ${ }^{5}$

I tillegg til å bosette israelske jøder i ØstJerusalem forsøker israelske myndigheter å begrense antallet palestinere som bor der. Da Israel annekterte Øst-Jerusalem i I967 ble palestinerne som bodde der tildelt såkalte «permanent residence permits» - permanent oppholdstillatelse. Denne tillatelsen gir palestinerne færre rettigheter enn de ville hatt med statsborgerskap. En av de viktigste ulempene er at tillatelsen når som helst kan inndras. Slik blir tilværelsen i ØstJerusalem en slags utvidet husarrest for unge palestinere: Dersom de bosetter seg midlertidig i en annen by for å studere, drar til utlandet, eller gifter seg med en palestiner fra Vestbredden og bosetter seg der, står de i umiddelbar fare for å miste oppholdstillatelsen og bli utestengt fra fødebyen. Dette er ingen tom trussel. I 2014 ble ro7 oppholdstillatelser inndratt, og mellom I967 og 20I4 har I4 48I tillatelser blitt inndratt. ${ }^{6}$ Dersom man som palestiner ønsker å ha en tilknytning til byen, er man dømt til å bli boende der resten av livet - og det er også nærmest umulig for palestinere utenfor Jerusalem å få oppholdstillatelse, slik at ekteskapsmarkedet i stor grad er begrenset til Øst-Jerusalem. ${ }^{7}$ Enhver jøde fra hvor som helst i verden kan imidlertid flytte dit når som helst og oppholde seg så lenge han/hun vil.

Separasjonsbarrieren som Israel har bygget langs store deler av grensen mellom Vestbredden og Israel er en tredje faktor som marginaliserer palestinere i Jerusalem. De blir isolert fra Vestbredden, og dessuten har palestinske nabolag blitt geografisk oppdelt. I størsteparten av Jerusalem har barrieren form av en flere meter høy betongmur, og den er bygget slik at flere palestinske nabolag (for eksempel 'Izariyya eller flyktningleiren Shu'fat) som offisielt tilhører Jerusalem kommune, og hvor innbyggerne har oppholdstillatelse, havner på østsiden av muren, altså på Vestbredden. Mange av innbyggerne har opp- 
holdstillatelse i Jerusalem og kan i prinsippet fremdeles komme inn til den andre siden, men må da gjennom sjekkpunktet. Her er det ofte lange køer, og de kan bli nektet innreise uten at soldatene trenger å oppgi noen grunn. Mer alvorlig er det kanskje at de har havnet i et slags administrativt limbo: De palestinske selvstyremyndighetene har ingen myndighet i disse om-

\section{2}

Jerusalem kommune har enkelt og greit latt være å bygge nok skoler i de østlige delene av Jerusalem over lang tid.

rådene, mens israelsk politi og andre offentlige tjenester overser dem siden de ligger på «feil» side av muren. Økt kriminalitet og mindre sosial sikkerhet er de uunngåelige konsekvensene.

For det fjerde sørger Jerusalem kommune for en ekstrem forskjellsbehandling av «israelske» og «palestinske» nabolag i byen. Der det bor israelere er infrastrukturen god, det er nok skoler, elektrisiteten fungerer som den skal, søppelet blir tømt og så videre. I Øst-Jerusalem blir søppelet gjerne liggende uten at kommunen frakter det bort, vann- og avløpsnettet er mangelfullt og veiene er dårlige, en tilstand som ble bemerket av israelske politikere allerede i i980-årene. ${ }^{8}$ Kommunen har også unnlatt å sonere og planlegge for områdene i øst, og for å få plass nok har vanlige palestinere blitt tvunget til å bygge nye hus eller bygge på allerede eksisterende hus uten tillatelse. I dag mangler cirka 39 prosent av palestinsk-eide bygg i Øst-Jerusalem byggetillatelse fordi dette er nesten umulig å oppnå. ${ }^{9}$ Dette brukes gjerne som påskudd av kommunen for å rive hus i øst, enten for å gi plass til bosettinger eller for å straffe familien til en eller annen motstandsaktivist. Når det ikke er uro eller opptøyer glimrer det israelske politiet med sitt fravær, noe som har ført til gode kår for lokale palestinske mafiaer og narkotikalangere. Som den lokale lederen for den katolske velferdsorganisasjonen Caritas uttalte til en avis: «If an Arab boy is arrested for throwing stones, he risks years in prison. But if kilos of heroin are sold on the street, no one does anything. How can one explain this?» ${ }^{10}$

Det siste punktet på denne lange klagelisten er også det alvorligste for unge: det elendige utdanningstilbudet. Jerusalem kommune har enkelt og greit latt være å bygge nok skoler i de østlige delene av Jerusalem over lang tid, og kommunen bruker i snitt dobbelt så mye penger på jødiske elever som palestinske. Resultatet er, ikke overraskende, at mellom 25 og 33 prosent av elevene på videregående faller ut av skolesystemet uten å fullføre. Dette igjen fører til at unge palestinere ofte er henvist til lavtlønnet arbeid i en by med svært høye levekostnader. Svimlende 74,3 prosent av befolkningen i Øst-Jerusalem lever under den israelske fattigdomsgrensen. ${ }^{11}$ Det absurde er at til tross for denne forskjellsbehandlingen, må palestinske innbyggere betale skatt til kommunen på lik linje med sine jødiske naboer.

\section{UNGE UTEN REPRESENTASJON}

Det er ikke bare levekårene til palestinere i ØstJerusalem som marginaliserer dem. Også mangelen på Iedere fører til fragmentering og ytterligere marginalisering, ikke minst i forhold til resten av palestinerne på Vestbredden. I 200I døde Faysal al-Husayni, den ubestridte lederskikkelsen blant palestinske jerusalemitter. Han var et framstående medlem av den viktige Husayni-familien, som historisk har vært en av to markante palestinske familier med stor formell og uformell makt. Han var en ruvende skikkelse i palestinsk politikk, populær blant utenlandske diplomater, og et kraftsentrum i PLO og Jerusalem. Han var også en karismatisk politiker 
som klarte å samle de ulike palestinske fraksjonene rundt felles formål. Al-Husayni opprettet et uformelt Jerusalem-hovedkvarter for PLO i Orient House, et gammelt herskapshus, i I980årene, og etter opprettelsen av de palestinske selvstyremyndighetene var han minister for Jerusalem-affærer. Han var en svært populær leder «innenfra» (det vil si at han hadde bodd på Vestbredden før 1993 og ikke kom fra eksilmiljøet i Tunisia), og ble sannsynligvis oppfattet som en rival av ledende skikkelser i Ramallah. Etter at alHusayni døde av hjerteinfarkt i 200 r har ingen andre fra Jerusalem greid å samle befolkningen. «Det finnes ikke noe lederskap i Jerusalem» og «det er ingen ledere som alle kan akseptere» var utsagn som gikk igjen $\mathrm{i}$ intervjuene mine.

Det er flere grunner til at Jerusalem ikke har et samlende politisk miljø. Man får gjerne høre av palestinerne selv at lederne i Ramallah egentlig ikke ønsker seg noe sterkt lokalt lederskap i Jerusalem - det kunne være en ubeleilig utfordring. Den mildere versjonen av dette synet er at Jerusalem ikke er en prioritet for De palestinske selvstyremyndighetene, som PLos ungdomskontor i Jerusalem fortalte meg. Ifølge dem er det tostatsløsningen som betyr mest for det politiske miljøet i Ramallah, og derfor fører de en politikk som stryker $\mathrm{EU}$ etter hårene, men som ikke hjelper Jerusalems befolkning: «Det er veldig vanskelig å navigere den palestinske politiske scenen og det internasjonale samfunnets prioriteringer - de passer ikke med virkeligheten som folk i Jerusalem lever i.» ${ }^{12}$

I mangel av vennligsinnet styre fra Israel og et sterkt og integrert lokalt lederskap har en mengde ulike grasrotorganisasjoner tatt ansvar for lokalsamfunnet og særlig de unges velbefinnende. Med ordet «grasrotorganisasjoner» mener jeg organisasjoner som har ideelle formål, som drives av aktivister rotfestet $\mathrm{i}$ et lokalt miljø og som jobber tett på «vanlige» folk. Det finnes en mengde slike organisasjoner i Øst-Jerusalem - en rapport fra 2015 oppgir at det er 347 registrerte sivilsamfunnsorganisasjoner i byen (bare Ramallah har flere) hvorav en stor del er grasrotorganisasjoner. ${ }^{13}$ Disse organisasjonene sikter mot å bevare og styrke det sosiale fellesskapet og tilliten i palestinske nabolag, å tilby unge jerusalemitter meningsfylte aktiviteter på fritiden, samt å organisere barnehagedrift og andre sosiale tjenester for en billig penge.

Et godt eksempel er Burj al-Laqlaq-foreningen i Jerusalems gamleby. Foreningen disponerer et stort område som ble donert av en velstående palestiner for å unngå at Israel bygget 840 bosetterleiligheter der en gang i I990-årene. Her har lokale aktivister bygget et senter som tilbyr leksehjelp, IT- og kunstundervisning, samt et utvalg idretter som håndball, fotball og taekwondo. De ansatte sier at hovedformålet deres er å støtte utdannelsen til jerusalemitter, som de betrakter som en av de største utfordringene palestinerne står overfor, gitt mangelen på skoler i byen. ${ }^{14}$ Et annet eksempel på grasrotaktivisme er organisasjonen Future Builders Forum, som ble startet av unge i bydelene Abu Dis, 'Izariyya og Sawahira i 2003. Disse bydelene ligger alle $\mathrm{i}$ limbo, utenfor muren, men innenfor Israels definisjon av Jerusalem kommune. Vanskelige leveforhold, kriminalitet og høyt frafall i skolen var bakgrunnen for etableringen av organisasjonen, som driver barnehage og kurser unge palestinere, med særlig vekt på kompetanseheving for unge kvinner. Ifølge aktivistene er frivillig arbeid grunnsteinen i organisasjonens arbeid. Tilliten og lojaliteten de har skapt ble kontrastert med fremmedgjøringen de føler overfor Israel og det palestinske lederskapet:

Det er hverken israelsk eller palestinsk politi her, vi lever i en lovlos virkelighet. Politiske autoriteter glimrer med sitt fravar, og vi har ikke noe leder- 
skap vi kan stotte oss til. Det krever at det finnes tillitsband mellom lederskapet og folket, og et slikt bånd finnes ikke. I stedet finner vi fragmentering. ${ }^{15}$

Disse og en rekke andre ideelle organisasjoner gjør en imponerende jobb under vanskelige forhold. Det sier seg imidlertid selv at de ikke kan erstatte mangelen på statlig og kommunalt organiserte velferdstjenester. Det beste de kan klare er å begrense skadevirkningene av det sosiale og politiske tomrommet unge palestinere i Jerusalem befinner seg i- og det er ikke nok.

De unge føler at de befinner seg i en blindgate. Utdanningsmulighetene er mangelfulle og fører dem uansett ingensteds hen, de har ikke borgerrettigheter og er annenrangs innbyggere i egen by, husene de bor i står gjerne i umiddelbar fare for å bli revet, foreldregenerasjonen kan ikke tilby støtte eller veiledning, og det finnes ikke noe organisert politisk miljø som kan støtte dem, noe som i sin tur fører til lavere tillit og solidaritet jerusalemitter imellom. Samtidig tillater ikke Israel unge fra Jerusalem å drive politisk aktivisme. De er henvist til et trangt rom for rent veldedig arbeid, selv om problemene deres i aller høyeste grad er politisk betinget. Kombinasjonen av disse faktorene har fort til en langsomt voksende og massiv krise i samfunnet. Selv aktivistene ser ganske svart på situasjonen. Som en av dem sa til meg:

Folk har begynt å fole på en identitetskrise bvordan kan vi leve, hvem er vi, hva bor vi gjore? Folk her i Jerusalem fokuserer bare på à overleve. De sliter som esler, unnskyld uttrykket, bare for à betale for forsikringen sin og for retten til a fortsette à bo i Jerusalem. De lider hver dag, bvert oyeblikk [...] Folk her begynner à bli gale. ${ }^{16}$

Det er i dette lyset vi må forstå knivangrepene. Det er essensielt å forstå at de overhodet ikke kom ut av det blå, som man gjerne kunne tro basert på de sensasjonspregede nyhetsoppslagene og det plutselige snakket om en «kniv-intifada». Angrepene ble tvert imot foregrepet og ledsaget av en bølge av større og mindre opptøyer og sammenstøt som kan kobles direkte til de umulige forholdene mange unge jerusalemitter lever under. En israelsk menneskerettighetsorganisasjon rapporterte i 2015 at «[i]n the summer of 20I4, the situation in East Jerusalem reached a boiling point following several years in which the tension and violence gradually escalated». ${ }^{17} \mathrm{I}$ løpet av juli-desember 2015 ble ir84 palestinere fra $\varnothing_{\text {st- }}$

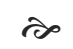

Det er søppel overalt, det stinker i sidegatene, veiene er for smale og i dårlig stand.

Jerusalem, blant dem 406 personer under 18 år, arrestert av israelsk politi og militære. Konfrontasjoner mellom unge palestinere (oftest menn) og israelsk politi og sikkerhetsstyrker fant sted på nesten daglig basis i 2015, som man kan se dersom man kikker raskt over kronologien som publiseres jevnlig av Journal of Palestine Studies. ${ }^{18}$

For å skjønne knivangrepene må man også skjønne sinnet som driver disse unge mennene som kaster stein og molotovcocktailer på israelske soldater. 'Isawiyya er et distrikt i Øst-Jerusalem der det ofte har vært kraftige sammenstøt mellom unge menn og israelsk politi og sikkerhetsstyrker. Så vidt jeg har kunnet bringe på det rene, er det kun ett samfunnshus i 'Isawiyya, og ingen internasjonale organisasjoner som jobber med innbyggerne der. Det er søppel overalt, det stinker i sidegatene, veiene er for smale og i dårlig stand, og friarealer eller parker kan innbyggerne bare drømme om. Men de har utsikt til østsiden av det israelske Hebrew University og Scopus-fjellet, 
med sine grønne friarealer. Dette er et sentralt punkt både når det gjelder opptøyene og knivangrepene: De unge palestinerne kan bare krysse en gate, og så kan de se et helt annet, komfortabelt liv som de selv er avskåret fra. De er imidlertid ikke fysisk avskåret fra det israelske samfunnet slik palestinere på Vestbredden er det, og derfor er muligheten for å konfrontere okkupasjonen mye større. Det er ganske enkelt lettere å nærme seg fienden.

Hvem er disse sinte unge mennene? De er gjerne arbeidsløse eller ufaglærte arbeidere, bundet sammen gjennom felles arbeidsplass, sine erfaringer med ydmykelse og undertrykkelse fra israelske myndigheter, og en æreskodeks hvor beskyttelsen av nabolaget står sterkt. Adel, veteran i ungdomsarbeidet og ansatt i UNDP Jerusalem, fortalte at disse mennene står for en ny, lokal og aggressiv aktivisme mot israelske myndigheter, og at de ikke har respekt for hverken foreldregenerasjonen eller israelsk politi. ${ }^{19}$

Konfrontasjonene mellom ungdom og israelsk politi er som oftest spontane affærer og gir derfor en god indikasjon på hvor frustrerte unge palestinere i Jerusalem er. På sitt sterkeste kan de faktisk ryste den israelske okkupasjonsmakten, slik det skjedde da folk i Shu'fat tok til gatene for vise sitt sinne og avsky over drapet på tenåringen Muhammad Abu Khudayr i juli 20I4 (Khudayr ble brent levende av en gjeng israelske nasjonalister som ville hevne drapet på to israelske gutter våren 2014). Folk i bydelen åpnet hjemmene sine for alle som deltok i protestene, og det strømmet til palestinere fra alle deler av Jerusalem som ville støtte ungdommene i Shu 'fat når de konfronterte israelsk politi. De voldsomme opptøyene spredte seg til andre områder, lammet deler av den sentrale veien gjennom Jerusalem, og var utfordrende for israelske sikkerhetsstyrker 760 jerusalemitter ble arrestert, hvorav 260 var barn. ${ }^{20}$
Men slike store opptøyer er unntaket. Sammenstøtene er oftest raske, spontane og planløse bluss av sinne og frustrasjon. Slik er de symptomer på politikkens fravær blant palestinere i Jerusalem snarere enn dens tilstedeværelse. Gatekampene med sikkerhetsstyrkene bunner ofte $i$ en revirmentalitet hvor nabolagets ære og integritet er de fundamentale verdiene. De større palestinske spørsmålene er henvist til kulissene. Motstanden i Øst-Jerusalems gater er reaktiv, mangler en samlende strategi og innebærer få eller ingen institusjonelle kontakter eller knutepunkter. Som en veteran fra den andre intifadaen bemerket:

De palestinske organisasjonene må utforme en strategi for a bekjempe okkupasjonen som inkluderer alle disse ungdommene [...] Det som skjer nå er ikke effektivt, for det dreier seg utelukkende om individuelle bendelser og handlinger. Det palestinske lederskapet involverer seg ikke i denne typen aktivisme, som er ineffektiv fordi den ikke er kollektiv. Vi må utforme én felles strategi for alle palestinere. ${ }^{21}$

Det er et paradoks at et slikt prosjekt er nærmest umulig å gjennomføre i Jerusalem, som har det nest høyeste antallet ikke-statlige organisasjoner i hele det okkuperte palestinske området. Men dette faktumet bare understreker hvor effektiv den dobbelte marginaliseringen av unge palestinere er $\mathrm{i}$ å fremme fragmentering og hindre mobilisering.

Når vi har kommet så langt, er det på tide å spørre seg hvor religionen blir av i dette bildet. Det er opplest og vedtatt at Jerusalem har en enormt viktig religiøs symbolfunksjon som har fungert mobiliserende ved flere anledninger, ikke minst i 2000, da Ariel Sharons spasertur på alHaram al-sharif (Tempelhøyden) var gnisten som antente den andre intifadaen. Selvmordsangrep er også noe som forbindes med islamistisk aktivisme, 
selv om sekulære grupper også har brukt taktikken. Hvilken rolle spiller islamsk ideologi i disse angrepene?

Al-Aqsa-moskeen er utvilsomt et svært kraftfullt symbol for muslimer generelt og palestinere spesielt, noe som tydelig vises $\mathrm{i}$ at Den islamske bevegelsen i Israel har fokusert mye av sin energi på å befeste det palestinske og muslimske eierskapet til dette hellige stedet. ${ }^{22}$ Det er desto mer interessant at religion generelt og islam spesielt er nærmest fraværende i intervjuene jeg har gjort. Da jeg selv tok initiativ til å bringe

\section{$\partial$}

Knivaktivistene har lite annet til felles med islamistiske selvmordsbombere enn at de fleste av dem ble drept.

temaet på bane var reaksjonen sjelden noe mer enn bekreftende nikk og selvfølgeligheter om at al-Aqsa og al-Haram al-sharif er røde linjer som ikke kan krysses. Men det var ikke helligdommene som sto i sentrum for aktivistene på noen måte. For enkelte var de lite mer enn billedskjønne friområder i den folketette Gamlebyen i Jerusalem. Selv om området rundt al-Aqsa-moskeen er et naturlig åsted for sammenstøt mellom palestinere og israelsk politi er det langt fra det eneste: Som vi har sett er bydelen 'Isawiyya et brennpunkt for slike sammenstøt, og det ligger langt unna al-Haram al-sharif.

Dette utelukker ikke at religiøse følelser var en medvirkende faktor i beslutningen til enkelte av knivangriperne. De siste årene før knivangrepene startet hadde spenningsnivået økt på al-Haram al-sharif som følge av at jødiske nasjonalister har trappet opp kampen om å dominere området enkelte ønsker å bygge et nytt tempel der. ${ }^{23} \mathrm{Al}-$ Haram al-sharif/Tempelhøyden er et nasjonalt og religiøst symbol av enorm betydning for både jøder og muslimer, og det er rimelig å tenke seg at oppfatningen om at de muslimske helligdommene er truet er en del av bildet når unge palestinere i Jerusalem bestemmer seg for å begå knivangrep. Både israelsk etterretning og foreldrene til noen av aktivistene la vekt på at de var ivrige brukere av sosiale medier, hvor de deltok i formidling av og diskusjon rundt rykter om at Israel ønsker å ta over al-Aqsa-området. ${ }^{24} \mathrm{De}$ såkalte murabitat - kvinnelige aktivister som ser det som sin oppgave å beskytte de islamske helligdommene i Jerusalem - besøkte familiene til noen av knivangriperne som ble drept.

Knivaktivistene har lite annet til felles med islamistiske selvmordsbombere enn at de fleste av dem ble drept før, under eller etter angrepet. Etter de første angrepene så man en smitteeffekt hvor folk med ulike oppfatninger og grader av tilhørighet til et organisert miljø lot seg inspirere, men de første angriperne var enkeltpersoner uten noen aktivisthistorie. Israelsk etterretning koblet dem heller ikke til Hamas eller Islamsk jihad. ${ }^{25}$

Det er altså ikke grunnlag for å si at islamsk ideologi eller Jerusalems symbolske status i seg gir noen god forklaring på knivangrepene og de stadige opptøyene rundt om i byen. Ut fra materialet jeg har presentert ovenfor mener jeg vi kan si at det er noe enda mer grunnleggende som står på spill, nemlig opplevelsen av å være permanent isolert og frarøvet muligheten til et verdig liv. Samtidig er man daglig i kontakt med de som står for dette røveriet og ser den enorme forskjellen i makt og muligheter på nært hold. Lederen for velferdssenteret i Burj al-Laqlaq i Gamlebyen fortalte at folk i Jerusalem simpelthen aldri kan la være å forholde seg til staten Israel og det israelske samfunnet, fordi det er så påtrengende. Derfor tvinger det seg fram en følelse av at noe må gjøres, men det finnes ingen ventil for denne følelsen. Innestengtheten og tomheten er overveldende: 
Det er presset som folk $i$ Jerusalem har folt på de siste 15-20 årene som fär unge til à lengte etter en eller annen forandring. Vi betaler alle slags skatter og avgifter, og de fleste bor $i$ veldig små leiligheter uten byggetillatelse. Jerusalem er som et fengsel. De tror at Vestbredden er som et fengsel, men da tenker de ikke på at Jerusalem er avstengt og ikke engang kan besøkes av folk fra Vestbredden, og at ingen israelere handler med palestinere i Jerusalem, for de har sine egne supermarkeder og kjopesentre ... På Vestbredden har de nesten en stat-forretningsliv, utdanning, alle disse tingene. I Jerusalem, ingenting.

Fortvilelsen unge føler er tydelig i disse få setningene, og i løpet av flere feltarbeid hørte jeg stadig spådommer à la «noe kommer til å skje, vi vet ikke hva, men det kan ikke fortsette slik». Slik sett er det grunnlag for å se opptøyene og knivangrepene som to sider av samme sak - som ulike svar på en uholdbar sosial og politisk situasjon. Dette er ikke spesielt kontroversielle ideer. Israelske aviskommentatorer og etterretningseksperter peker på de samme elementene, selv om språket kan arte seg annerledes enn det jeg har brukt her. En rapport fra et israelsk kontraterrorisme-senter ser for eksempel knivangrepene som en indikasjon på

[the] depth of the frustration and desperation felt by the younger generation of Palestinians at the forefront of the wave of attacks. [...] They are frustrated by what seems to them as the ongoing Israeli occupation, disappointed by the $P A$ and apparently also by the Palestinian terrorist organizations. ${ }^{26}$

Ved å angripe israelere med kniv forlater unge palestinere et liv de føler er umulig (siden de må regne med å bli drept i forsøket). Mangelen på institusjoner og et organisert sosialt liv, som jeg har skissert i denne artikkelen, forklarer også den spektakulære måten knivangrepene skjer på. Man tar det enkleste våpenet man kan finne, finner det første og beste offeret, og er i stand til å angripe nettopp fordi man ikke lenger har noen selvoppholdelsesdrift, et liv man instinktivt ønsker å ta vare på.

\section{KONKLUSJON}

Det er et problem av store dimensjoner som reiser seg her. Når en hel generasjon unge palestinere i Jerusalem har lært seg å hate sine liv og den israelske staten, og bare har forakt til overs for sitt eget lederskap, hva er da mulighetene for å kontrollere dem, eller for å få dem til å støtte opp om avtaler mellom det palestinske lederskapet og Israel? Slik sett er det skremmende fenomenet med knivdesperadoer et monster skapt av Israels okkupasjon og åpenbare diskriminering av palestinerne i Øst-Jerusalem. I et politisk perspektiv vil man sannsynligvis gjøre vel i å huske at Jerusalem er mer enn et religiøst brennpunkt. Det er en by hvor vanlige mennesker prøver å leve vanlige liv, men igjen og igjen møter uoverstigelige hindre, og ser at dagliglivet blir vanskeligere og vanskeligere å få til å gå rundt. Det er dette som ligger bak de fragmenterte og uorganiserte voldsutbruddene i byen, ikke nasjonalistisk eller religiøs ideologi. Volden i Jerusalem er kort sagt en konsekvens av et langsomt sosialt og politisk sammenbrudd, og unge palestinere $\mathrm{i}$ byen er i ferd med å miste balansen.

\section{- $f \cdot$}

JACOB HøIGILT er førsteamanuensis II på Institutt for kulturstudier og orientalske språk ved Universitetet i Oslo og seniorforsker hos PRIO.

1 For detaljer om angrepene høsten 2015, se nettsidene til den palestinske menneskerettighetsorganisasjonen al-Haq: alhaq.org/documentation/field-updates-2015/971palestinians-killed-in-the-opt-since-1-october-2015. 


\section{Å BALANSERE PÅ EN KNIVSEGG}

2 Hoffman, Ariela Ringel: “This Isn't a Lone Wolf Intifada, It's a Hamas Intifada”, i Ynetnews, 13. mars 2013, ynetnews.com/articles/0,7340,L-4777045,00.html.

3 "Dangerous Liaison: The Dynamics of the Rise of the Temple Movements and Their Implications". Ir Amim, 2013, ir-amim.org.il/sites/default/files/Dangerous\%20LiaisonDynamics\%20of\%20the\%20Temple\%20Movements.pdf.

4 Bowen, Jeremy: "Jerusalem Knife Attacks: Fear and Loathing in Holy City", i BBC News, 15. oktober 2015, bbc.com/news/world-middle-east-34543808.

5 Se btselem.org/settlements/statistics for disse tallene.

6 Se B'Tselems nettside om temaet, btselem.org/jerusalem/ revocation_statistics (13.09.2016)

7 Se B'Tselems nettside om temaet, btselem.org/family separation/east_jerusalem (13.09.2016).

8 Cheshin, Amir, Bill Hutman, og Avi Melamed: Separate and Unequal: The Inside Story of Israeli Rule in East Jerusalem. Cambridge, MA: Harvard University Press, 2001, s. 229.

9 Association for Civil Rights in Israel (ACRI): "East Jerusalem 2015 - Facts and Figures”. Association for Civil Rights in Israel, 2015, s. 7, acri.org.i1/en/2015/05/12/ej2015/.

10 "The Director of Caritas Jerusalem: There Is Also a Political Use of the Drug Market in the Holy City ", i Fides News Agency, 4. juli 2014, fides.org/en/news/36022-ASIA HOLY_LAND_The_Director_of_Caritas_Jerusalem_ there_is_also_a_political_use_of_the_drug_market_ in_the_Holy_City\#.VnKHFEorKU1.

11 Association for Civil Rights in Israel (ACRI): "East Jerusalem 2015 - Facts and Figures”. Originalrapporten på hebraisk finnes på btl.gov.i1/Publications/oni_report/Pages/oni2013.aspx.

12 Intervju med Mazin al-Ja’bari, Youth Development Center (tidligere del av Orient House), Bayt Hanina, 15. januar 2013.

13 Costantini, Gianfrancesco, Estephan Salameh, og Maher Issa: "Mapping Study of Civil Society in Palestine - Update 2015”. Transtec, 2015, s. 19, eeas.europa.eu/delegations/ westbank/documents/news/2015/pal_csomapping_ 2015.pdf.

14 Intervju med "Ya’qub", Jerusalem, 30. mai 2015.

15 Intervju med "Manal", Abu Dis, 11. april 2013.

16 Intervju med “Obay”, Jerusalem, 30. mai 2015.

17 Association for Civil Rights in Israel (ACRI): "East Jerusalem 2015 - Facts and Figures", s. 12.

18 Kronologien finnes på palestine-studies.org/jps/chronologies.

19 Intervju med “Adel”, Jerusalem, 28. mai 2015.
20 Kershner, Isabel: “Arab Boy's Death Escalates Clash Over Abductions", i The New York Times, 2. juli 2014, nytimes.com/2014/07/03/world/middleeast/israel.html; Levy, Gideon: "Jerusalem, the Capital of Apartheid, Awaits the Uprising”, i Haaretz, 23. oktober 2014, haaretz.com/opinion/.premium-1.622206.

21 Intervju med "Muhammad", Jerusalem, 30. mai 2015.

22 Larkin, Craig og Michael Dumper: "In Defense of Al-Aqsa: The Islamic Movement inside Israel and the Battle for Jerusalem", i The Middle East Journal, vol. 66, no. 1, 2012, s. $30-51$.

23 "Al-Aqsa Mosque Compound Targeted: Lurking Dangers Between Politics and Prophecies". Jerusalem: Palestinian Academic Society for the Study of International Affairs, 2015; "Dangerous Liaison: The Dynamics of the Rise of the Temple Movements and Their Implications."

24 Beaumont, Peter: "What's Driving the Young Lone Wolves Who Are Stalking the Streets of Israel?", i The Guardian, 18. oktober 2015, theguardian.com/world/2015/oct/18/knifeintifada-palestinian-israel-west-bank.

25 Ibid.; "Initial Findings of the Profile of Palestinian Terrorists Who Carried Out Attacks in Israel in the Current Wave of Terrorism (Updated to October 25, 2015)". The Meir Amit Intelligence and Terrorism Information Center, 2015, terrorism-info.org.il/en/articleprint. aspx?id=20900 (31.12.2015).

26 "Initial Findings of the Profile of Palestinian Terrorists Who Carried Out Attacks in Israel in the Current Wave of Terrorism (Updated to October 25, 2015)". 